PENELITIAN

\title{
Pemberian Lidokain 1,5 mg/Kg/Jam Intravena untuk Penatalaksanaan Nyeri Pasien Pasca Laparatomi
}

\author{
Dicky Hartawan*, Hariyo Satoto**, Uripno Budiono** \\ * Bagian Anestesiologi dan Terapi Intensif RSUD Tarakan, Kalimantan Timur \\ ** Bagian Anestesiologi dan Terapi Intensif FK UNDIP/ RSDK
}

\begin{abstract}
Background: An effective post operative pain management is an important thing and one of the problem for anaesthesiologist. One of the surgery with high pain level postoperative is laparotomy. Previous study show that IVLI (intravenous lidocaine infusion) is effective to reduce post operative pain for abdominal surgery.

Objectives: Understanding the use of lidocaine intravena $1,5 \mathrm{mg} / \mathrm{kg} / \mathrm{hr}$ as an alternative for post operative pain management for laparotomy.

Method: This study is an clinical experimental study with non-randomized blind design in Central Operating Theatre of Kariadi Hospital Semarang. Sample was taken from laparotomy patient using consecutive sampling and divided to two group. The first group was given lidocaine $1 \mathrm{mg} / \mathrm{kg} / \mathrm{iv} 30$ minute before skin incision and continued with lidocaine $1,5 \mathrm{mg} / \mathrm{kg} / \mathrm{iv}$ until 48 hours postoperative. Second group was given placebo. VAS (Visual Analog Score) and hemodynamic parameter postoperative of patient was measured, if VAS was more than 5 than patient got a rescue analgesia. Statistical analytic with SPSS 17 for Windows.
\end{abstract}

Result: Postoperative there was significant difference between groups in the need of rescue analgesia (4 vs 15 subject respectively, $p=0.01)$, the use of opioid $(12,9 \pm 1,53$ vs $16,57 \pm 2,59 \mathrm{mg}$ respectively, $p=0.01)$, VAS 12 hours $(3,8 \pm 0,88$ vs 5,3 $\pm 0,56$ respectively,

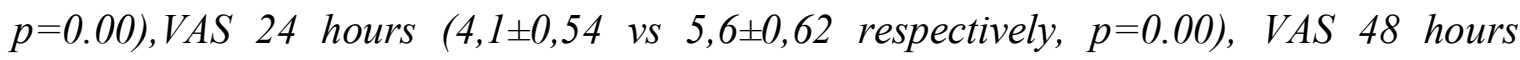
(4,5 $\pm 0,51$ vs $5 \pm 0,0$ respectively, $p=0,02)$, and the heart rate $(p=0.00)$.

Conclusion: The injection of intravenous lidocaine $1,5 \mathrm{mg} / \mathrm{kg}$ is effective in pain management for post laparotomy and reduce the use of analgetic opioid in pain management for post laparotomy.

Keywords: intravenous lidocaine, VAS, hemodynamic

\section{ABSTRAK}

Latar Belakang: Penanggulangan nyeri post operasi yang efektif merupakan salah satu hal yang penting dan menjadi problema bagi ahli anestesi. Salah satu jenis pembedahan dengan tingkat nyeri pasca operasi tinggi adalah laparotomi. Menurut penelitian terdahulu IVLI (intravenous lidokain infusion) berpotensi dan efektif untuk mengurangi nyeri paska operasi pada kasus bedah abdominal.

Tujuan: Mengetahui apakah penggunaan lidokain intravena $1,5 \mathrm{mg} / \mathrm{kg} / \mathrm{jam}$ dapat menjadi salah satu alternatif pengelolaan nyeri paska operasi laparotomi 
Metode: Penelitian ini merupakan uji eksperimental klinis dengan desain acak tersamar di Instalasi Bedah Sentral (IBS) RSUP Dr. Kariadi Semarang. Sampel diambil dari pasien yang menjalani operasi laparatomi menggunakan "consecutive sampling" dan dibagi menjadi dua kelompok: Kelompok 1 (K1) diberikan lidokain $1 \mathrm{mg} / \mathrm{kg} / \mathrm{iv} 30$ menit sebelum insisi kulit dan dilanjutkan dengan lidokain 1,5mg/kg/jam sampai 48 jam paska operasi; Kelompok 2 (K2) diberikan plasebo. Pasien dinilai Score Analog Visual dan parameter hemodinamik post operatif, bila $S A V>5$ pasien mendapatkan rescue analgesia. Analisis statistik dengan SPSS for Windows versi 17.

Hasil: Pasca operasi terdapat perbedaan bermakna pada kebutuhan rescue analgesia (4 vs 15 subjek, $p=0.01$ ), waktu dimulainya rescue analgesia(jam ke 18.0 0.92 vs $14.5 \pm 5.19, p=0.01)$, penggunaan opioid $(12,9 \pm 1,53$ v $16,57 \pm 2,59 \mathrm{mg}, p=0.01)$, VAS 12

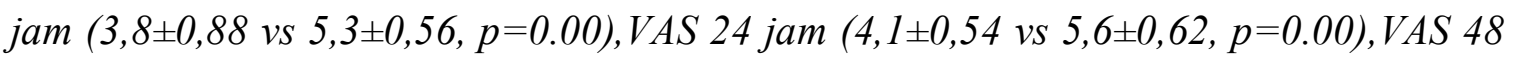
jam $(4,5 \pm 0,51$ vs $5 \pm 0,0, p=0,02)$, dan laju jantung $(p=0,00)$ kedua kelompok

Simpulan: Pemberian Lidokain 1,5 $\mathrm{mg} / \mathrm{kg}$ intravena cukup efektif dalam pengelolaan nyeri post laparotomi dan dapat menurunkan kebutuhan penggunaan analgetik opioid dalam pengelolaan nyeri post laparotomi.

Kata Kunci: lidokain intravena, SAV, nyeri paska laparatomi.

\section{PENDAHULUAN}

Nyeri bukan hanya suatu modalitas sensorik tetapi adalah suatu pengalaman. The International Association for the Study of Pain menggambarkan nyeri sebagai "suatu pengalaman sensoris dan emosional yang tidak menyenangkan dihubungkan dengan kerusakan jaringan nyata atau potensial terjadinya kerusakan jaringan, atau digambarkan dalam keadan yang berkaitan dengan kerusakan tersebut." Definisi ini saling mempengaruhi antara tujuan, aspek sensoris fisiologis nyeri dan sifat subyektifnya, emosional, dan komponen psikologis. Tanggapan untuk nyeri dapat sangat bervariasi pada berbagai orang sebagaimana pada orang yang sama pada waktu yang berbeda. ${ }^{1,2}$

Nyeri bukanlah akibat sisa pembedahan yang tak dapat dihindari melainkan suatu komplikasi yang bermakna pada sebagian besar pasien. Penanggulangan nyeri pasca operasi yang efektif merupakan salah satu hal yang penting dan menjadi problema bagi ahli anestesi. Hal tersebut disebabkan berbagai hal sebagai berikut: 1. Nyeri pasca operasi sangat bersifat individual, tindakan yang sama pada pasien yang kurang lebih sama keadaan umumnya tidak selalu mengakibatkan nyeri pasca operasi yang sama. Pengalaman penderita terhadap derajat atau intensitas nyeri pasca operasi sangat bervariasi. 2. Banyak pasien yang kurang mendapat terapi nyeri yang adekuat pasca operasi. 3. Bebas nyeri dapat mengurangi komplikasi pasca operasi. ${ }^{1,3-6}$

Nyeri pasca operasi sangat unik dan merupakan salah satu jenis nyeri akut yang sering terjadi. Beberapa penelitian 
menunjukkan bahwa protokol penanganan nyeri yang tepat mampu menurunkan morbiditas, meningkatkan kualitas hasil pembedahan dan dapat menurunkan biaya rumah sakit. Penanganan nyeri pasca operasi yang cukup berhubungan dengan efek jangka panjang yang positif terhadap pasien, contohnya: menurunkan perubahan kognitif pasca operasi, kualitas hidup yang lebih baik, dan menurunkan resiko terjadinya nyeri kronik pasca operasi. ${ }^{1,7}$

Dari segi pembedahan, lokasi nyeri pasca operasi yang paling sering terjadi dengan tingkat nyeri yang hebat (severe) misalnya operasi daerah thoracoabdominal, operasi ginjal, operasi columna vertebralis (spine), operasi tulang panjang (large bone) di ekstremitas. ${ }^{2,4,6,8}$

Sekitar $50-70 \%$ pasien yang menjalani pembedahan mengalami nyeri sedang sampai berat, hal ini menunjukkan meskipun terjadi perkembangan obat dan tehnik analgetik yang baru masih tetap memerlukan pengelolaan yang lebih baik lagi. Manajemen nyeri pasca operasi yang terbaik adalah dengan pendekatan analgesia multi modal, termasuk dalam hal ini metode dengan regional anestesi atau analgesi sistemik contohnya golongan opioid, non steroid antiinflamatory drug (NSAID) dan lainlain. Pendekatan analgesia multi modal lebih efektif dalam manajemen nyeri dibandingkan penggunaan opioid dosis tunggal. Adakalanya pendekatan ini bisa menjadi beban dengan biaya yang lebih mahal atau adanya beberapa kontra indikasi obat pada pasien. ${ }^{1,3,4,7}$

Data metaanalysis randomize control trial tahun 2011 oleh Vigneault menyatakan bahwa Pemberian IVLI (intravenous lidocain infusion) selama anestesi umum berpotensi dan efektif untuk mengurangi nyeri pasca operasi pada kasus bedah abdominal. Lidokain intravena mampu mengatasi nyeri pasca operasi secara signifikan dengan turunnya tingkat nyeri, konsumsi obat anestesi inhalasi dan opioid dapat dikurangi, fungsi pencernaan cepat pulih dan produksi interleukin berkurang sehingga masa perawatan dan pemulihan pun lebih cepat. Hal tersebut selain harga lidocain yang relatif lebih murah dan dapat menurunkan biaya perawatan bagi pasien. Kemampuan analgetik lidokain dapat bertahan meskipun kadarnya dalam plasma turun, sesuai dengan teori blokade konduksi saraf. Bryson et al (2010) menggunakan lidocain intravena $1,5 \mathrm{mg} / \mathrm{kg}$ bolus dan dilanjutkan $3 \mathrm{mg} / \mathrm{kg} / \mathrm{jam} / \mathrm{iv}$ pada abdominal histerektomi. ${ }^{1,5}$

Penelitian ini bertujuan untuk mengetahui apakah penggunaan lidocain $1,5 \mathrm{mg} / \mathrm{kg} / \mathrm{jam}$ intravena dapat menjadi salah satu alternatif pengelolaan nyeri pasca operasi laparatomi.

\section{METODE}

Penelitian ini merupakan uji eksperimental klinis dengan desain non acak tersamar. Sampel diambil dari pasien yang menjalani operasi laparatomi di Instalasi Bedah Sentral 
RSUP Dr. Kariadi Semarang, menggunakan "consecutive sampling" dibagi menjadi dua kelompok. Kelompok 1 (K1) diberikan lidokain $1 \mathrm{mg} / \mathrm{kg} / \mathrm{iv} 30$ menit sebelum insisi kulit dan dilanjutkan dengan lidocain 1,5mg/ $\mathrm{kg} / \mathrm{jam}$ sampai 48 jam pasca operasi, sedangkan Kelompok 2 (K2) diberikan plasebo. Penelitian ini menggunakan sampel sejumlah 48 orang, dibagi menjadi 2 kelompok, masing masing 24 orang dengan kriteria Pasien berusia 1860 tahun, Status fisik ASA I-II, Operasi laparatomi dengan anestesi umum di RSUP Dr. Kariadi Semarang, dan menyetujui diikutsertakan dalam penelitian. Pasien dieksklusikan bila memiliki nyeri kronik, sedang mendapat opioid \pm 7 hari sebelum operasi, durante operasi mengalami komplikasi anestesi maupun pembedahan, riwayat alkoholik., kelainan psikis, penyakit kardiovaskuler akut dan atau dengan gangguan block konduksi jantung, penyakit susunan saraf pusat karena tidak bisa komunikasi, Alergi terhadap lidokain, pethidin, tramadol, ketorolac, morfin, atau riwayat Seizure.

Pada saat masuk ke kamar operasi, tekanan darah sistolik (TDS), tekanan darah diastolik (TDD), tekanan arteri rerata (TAR), laju jantung (LJ), diukur 30 menit sebelum diberikan lidokain $1 \mathrm{mg} / \mathrm{kg} / \mathrm{iv}$, evaluasi hemodinamik diulang sebelum dilakukan induksi anestesi dan semua penderita diberikan premedikasi midazolam $2 \mathrm{mg} /$ iv 2 menit sebelum induksi. Induksi dilakukan dengan menggunakan propofol $2 \mathrm{mg} / \mathrm{kgBB}$. Setelah refleks bulu mata hilang, diberikan vecuronium bromide $0,1 \mathrm{mg} / \mathrm{kgBB}$, kemudian dilakukan intubasi endotrakeal, setelah itu diberikan pethidin $1 \mathrm{mg} / \mathrm{kg} / \mathrm{iv}$. Rumatan anestesi dengan menggunakan isofluran 1,2 vol\%, Air 30\% dan $\mathrm{O}_{2}$ $50 \%$. Lidokain $1,5 \mathrm{mg} / \mathrm{kg} / \mathrm{jam}$ atau plasebo dijalankan setelah dilakukan intubasi. Jika diperlukan, vecuronium bromide intermiten diberikan dengan dosis $0,05 \mathrm{mg} / \mathrm{kgBB}$. Hemodinamik diukur segera setelah dilakukan induksi. Obat anestesi inhalasi dihentikan pada akhir operasi. Analgetik pasca operatif ketorolak 0,5 mg $/ \mathrm{kg} / \mathrm{iv}$ diberikan 30 menit sebelum ekstubasi, dan diulang tiap 8 jam. Lidokain $1,5 \mathrm{mg} / \mathrm{kg} / \mathrm{jam}$ atau placebo dilanjutkan sampai 48 jam pasca operasi.

Nyeri dinilai dengan VAS, apabila pasien tetap merasa nyeri (VAS $>5$ ) akan di berikan recue analgetik serta dicatat pada jam atau menit keberapa membutuhkan opioid. Pasien dengan efek samping dilaporkan, namun pemberian lidokain dihentikan dan tidak dimasukkan dalam analisis.

Evaluasi tekanan darah sistole tekanan darah diastol, tekanan areteri rata-rata, laju jantung, Saturasi $\mathrm{O}_{2}$ dan Score Analog Visual dilakukan setelah pasien sadar dan kooperatif (60 menit, 6 jam, 12 jam,24 jam dan 48 jam pasca operasi).

Data yang terkumpul telah dilakukan cleaning, coding dan tabulasi. Data dikumpulkan dan diolah dengan menggunakan program SPSS 15.0 for 
windows.

\section{HASIL}

Sebanyak 50 pasien laparotomi masuk dalam kriteria inklusi dalam sampel penelitian. Pasien berkenan dimasukan dalam penelitian dan menyetujui inform concent. Selanjutnya pasien dikelompokkan dalam kelompok lidokain intravena (I) sebanyak 26 pasien dan placebo(II) sebanyak 24 pasien.

Sebanyak 2 orang subjek dieksklusikan karena mengalami kejadian tak diharapkan yaitu satu subyek dengan bradikardi dan satu subjek dengan perdarahan masif. Keduanya dari kelompok lidokain (I).Subyek tersebut tidak diikutsertakan dalam analisis akan tetapi profilnya akan dibahas lebih lanjut. Dengan demikian, sampel penelitian ini adalah sebanyak 24 pasien dari kelompok I dan 24 pasien dari kelompok II .

Data Visual Analog Score (VAS) pada 6 jam, 12 jam, 24 jam dan 48 jam pasca operatif memiliki sebaran yang tidak normal, maka dilakukan uji nonparametrik Mann-Whitney, sedangkan data umur, berat badan, waktu pemberian rescue analgetik, jumlah morfin yang diberikan, dan parameter hemodinamik yang dinilai ( heart rate, tekanan sistolik, diastolik dan tekanan arteri rerata pada $6,12,24$ dan 48 jam pasca operatif) berdistribusi normal maka dilakukan uji t independen 2 arah.
Pada Tabel 1 diperlihatkan data dasar. subjek. Umur rerata kelompok I 51.04 \pm 7.765 tahun, tidak berbeda bermakna dengan rerata umur kelompok II yaitu $51.25 \pm 8.01 \quad(\mathrm{p}=0,928)$. Kelompok I terdiri dari 8 orang laki - laki dan 16 orang perempuan., secara statistik tidak berbeda bermakna dengan kelompok II yaitu 12 orang laki - laki dan 12 orang perempuan $(\mathrm{p}=0,248)$. Tidak dijumpai perbedaan bermakna untuk parameter umur, BB, dan Parameter hemodinamik awal kedua kelompok sebelum pemberian tindakan. Pada kedua kelompok, sebagian besar subjek adalah pasien pasca operasi bedah Digestif (tabel 2)

Sepanjang penelitian ini sebanyak 19 subjek membutuhkan rescue analgesia, yaitu 4 orang dari kelompok I dan 15 orang pada kelompok II ( $p=0,001)$. Pada kelompok I ke 4 orang subjek tersebut mulai diberikan rescue analgesia pada 12 -24 jam pasca operatif. Pada kelompok II 9 orang subjek mulai diberikan rescue analgesia antara 6-12 jam pasca operatif,sedangkan 6 subjek mulai diberikan rescue analgesia pada 12-24 jam pasca operatif. Tidak ada subjek yang mulai diberikan rescue analgesia sebelum 6 jam pasca operatif dan setelah 24 jam pasca operatif. Rerata waktu mulai dibutuhkannya rescue analgesia jumlah opioid yang digunakan antar kedua kelompok, juga berbeda bermakna $(\mathrm{p}=0.01)$

Pada SAV dan hemodinamik subjek 6 jam pasca operasi, didapatkan perbedaan tidak bermakna, namun pada 
Tabel 1 KarakteristikAwal SubyekPenelitian

\begin{tabular}{llll}
\hline Parameter & I & II & $p^{*}$ \\
\hline Jenis Kelamin(L:P) & $8: 16$ & $12: 12$ & 0.248 \\
Umur & $51.04 \pm 7.765$ & $51.25 \pm 8.01$ & 0.928 \\
BB & $56,25 \pm 12.45$ & $58,08 \pm 12.68$ & 0.616 \\
TD Systolik & $126.46 \pm 14.518$ & $129.79 \pm 15.567$ & 0.447 \\
TD Diastolik & $74.33 \pm 11.941$ & $73.75 \pm 10.242$ & 0.857 \\
MAP & $91.7083 \pm 12.33874$ & $92.4306 \pm 9.58031$ & 0.822 \\
Laju Jantung & $75.25 \pm 7.379$ & $76.21 \pm 9.891$ & 0.705 \\
\hline
\end{tabular}

* bermakna bila $p<0.05$

Tabel 2. Jenis pembedahan masing-masing kelompok

\begin{tabular}{lllll}
\hline & Kelompok I & \multicolumn{3}{l}{ Kelompok II } \\
\cline { 2 - 5 } Jenis Pembedahan & Jumlah & Persentase & Jumlah & Persentase \\
\hline Digestif & 12 & 25.00 & 14 & 29.16667 \\
Urologi & 2 & 4.166667 & 2 & 4.166667 \\
Ginekologi & 10 & 22.91667 & 8 & 16.66667 \\
\hline
\end{tabular}

$* p=0,12$. bermakna bila $p<0.05$

Tabel3. Pemberian Rescue Analgesia

\begin{tabular}{llll}
\hline & I & II & $\mathbf{P}^{*}$ \\
\hline$<\mathbf{6}$ jam pasca op & 0 & 0 & \\
6-12 jam pasca op & & & \\
$\mathbf{1 2 - 2 4}$ jam pasca op & 2 & 9 & \\
$>\mathbf{2 4}$ jam pasca op & 2 & 6 & \\
\hline Total Penerima(subjek) & 0 & 0 & 0.01 \\
\hline Rerata Waktu Mulai Diberikan & 4 & 15 & 0.01 \\
(post op jam) & & $14.5 \pm 5.19$ & \\
\hline Opioid dibutuhkan (mg) & $12,9 \pm 1,53$ & $16,57 \pm 2,59$ & 0,01 \\
\hline
\end{tabular}

(*bermakna bila $\mathrm{p}<0.05$ ) 
pemeriksaan jam ke12 dan 24 pasca operasi, SAV dan Laju jantung kedua kelompok berbeda bermakna.

Rerata SAV pada 6 jam pasca operasi kelompok I adalah $3.2 \pm 0,56$, sedangkan

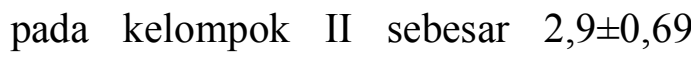
$(\mathrm{p}=0,259)$. Tekanan darah dan laju jantung antar kelompok pada 6 jam pasca operasi berbeda tidak bermakna.

Pada 12 jam pasca operasi terdapat perbedaan SAV dan hemodinamik yang bermakna antar kedua kelompok. SAV kelompok I adalah sebesar $3,8 \pm 0,88$, dan SAV kelompok II adalah 5,3 $\pm 0,56$ $(p=0,00)$.

Pada 24 jam pasca operasi terdapat perbedaan SAV dan hemodinamik yang bermakna antar kedua kelompok. SAV kelompok I adalah sebesar 4,1 $\pm 0,54$, dan SAV kelompok II 5,6 $\pm 0,62$ adalah $(p=0.00)$.

Pada 24 jam pasca operasi terdapat perbedaan SAV dan hemodinamik yang bermakna antar kedua kelompok. SAV kelompok I adalah sebesar 4,5 $\pm 0,51$, dan SAV kelompok II 5,0 $\pm 0,00$ adalah $(p=0.02)$

Laju jantung berbeda bermakna pada 12 jam ,24 jam dan pada 48 jam pasca operasi dengan $\mathrm{p}=0,00$.

\section{PEMBAHASAN}

Nyeri pasca operasi sangat unik dan merupakan salah satu jenis nyeri akut yang sering terjadi.Penelitian menunjukkan bahwa protokol penanganan nyeri yang tepat mampu menurunkan morbiditas dan berhubungan dengan efek jangka panjang yang positif terhadap pasien. Laparotomi adalah salah satu jenis pembedahan dengan tingkat nyeri pasca operatif yang tinggi. Pengelolaan nyeri pasca operatif pada jenis pembedahan ini sebagian besar melibatkan analgetik opioid dengan segala resikonya. Lidokain intravena memiliki efek analgetik dan antiinflamasi sehingga berpotensi digunakan dalam pengelolaan nyeri pasca laparotomi.

Hasil penelitian ini menunjukkan bahwa pada kelompok pasien yang dberikan lidokain intravena durante operasi dan dilanjutkan hingga 48 jam pasca operatif, tingkat nyeri yang diderita lebih rendah daripada kelompok placebo.Hal ini tercermin pada jumlah pasien yang membutuhkan rescue analgesi (4:15 subjek). Hasil ini sesuai dengan pernyataan Barros bahwa lidokain intravena efektif sebagai analgetik pasca operatif pada bedah abdomen. ${ }^{1}$

Pada penelitian ini kami temukan bahwa pada kelompok pasien yang mendapatkan lidokain IV laju jantung dan SAV pada 12 jam, 24 jam dan 48 jam pasca operatif berbeda bermakna dengan kelompok placebo. SAV sebagai alat ukur nyeri, memang bersifat subjektif pada masing masing individu, namun demikian dalam konteks persepsi nyeri, maka SAV adalah piranti yang akurat untuk menilai persepsi subjek tersebut terhadap nyeri yang diderita. Secara lebih objektif, perubahan keadaan hemodinamik juga dapat 
Tabel 4. Data SAV Antar Dua Kelompok

\begin{tabular}{llllll}
\hline \multirow{2}{*}{ Waktu } & \multicolumn{3}{l}{ Kelompok } & & \\
\cline { 2 - 5 } & I & & II & N \\
\cline { 2 - 5 } & n Subjek & SAV & n Subjek & SAV & \\
\hline 6 jam pasca op & 24 & $3.2 \pm 0,56$ & 24 & $2,9 \pm 0,69$ & 0,259 \\
12 jam pasca op & 24 & $3,8 \pm 0,88$ & 23 & $5,3 \pm 0,56$ & 0.00 \\
24 jam pasca op & 22 & $4,1 \pm 0,54$ & 11 & $5,6 \pm 0,62$ & 0.00 \\
48 jam pasca op & 20 & $4,5 \pm 0,51$ & 9 & $5 \pm 0,0$ & 0,02 \\
\hline
\end{tabular}

* bermakna bila $\mathrm{p}<0.05$

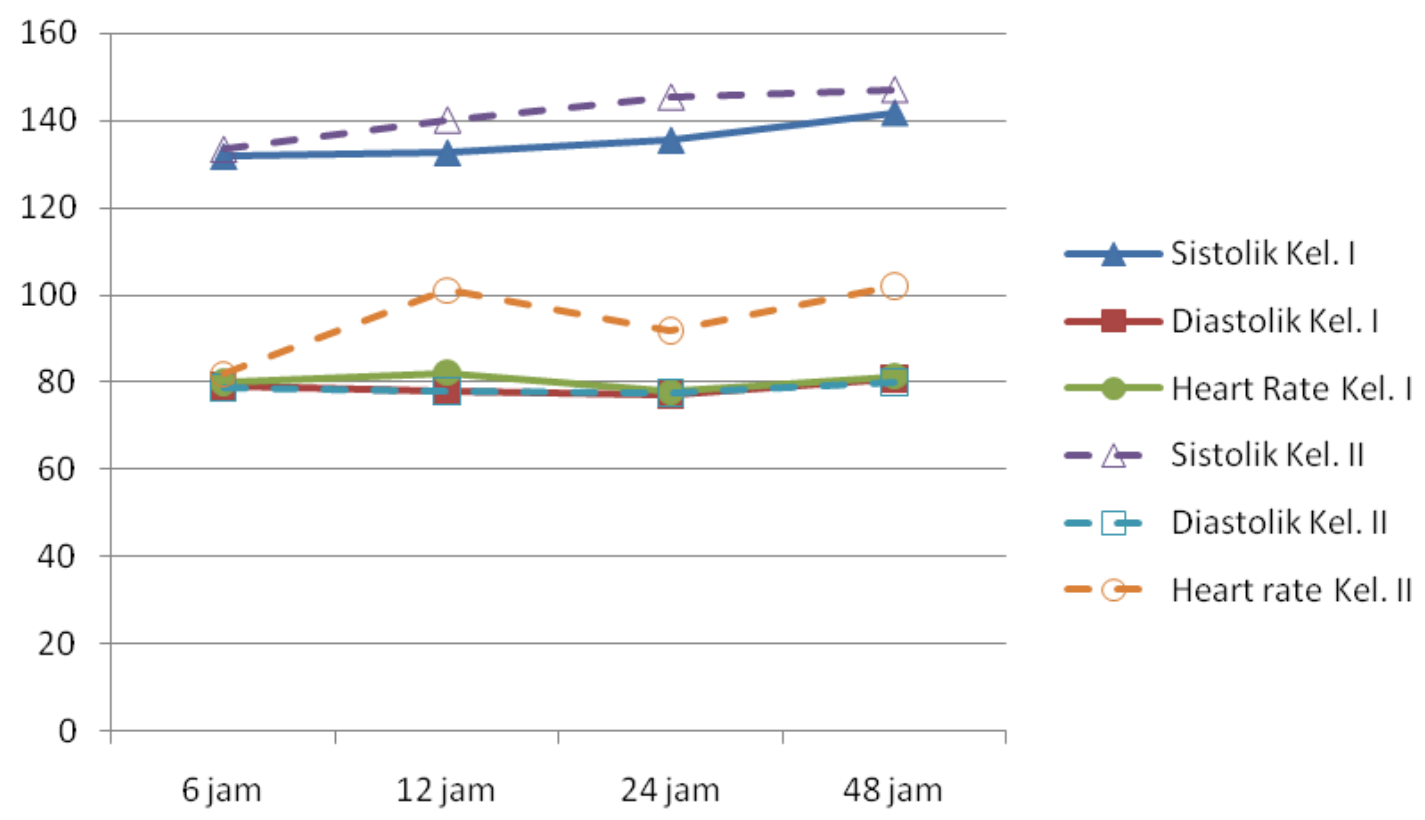

Gambar 1. Hemodinamik pasca operasi 
menggambarkan nyeri yang sedang dialami subjek. Pada subjek yang mengalami nyeri, akan terjadi peningkatan pelepasan katekolamin endogen sehingga menyebabkan parameter hemodinamik, diantaranya laju jantung, akan meningkat. Pada subjek yang mendapatkan lidokain intravena, terjadi peningkatan SAV dalam 12 jam pasca operatif, meski demikian, pada kelompok placebo peningkatan tersebut jauh lebih tinggi dan perbedaan antar kedua kelompok bermakna. Hal serupa terjadi pula pada nilai laju jantung antar kedua kelompok dimana pad a kelo m pok placebo,peningkatan tertinggi terjadi pada 12 jam pasca operasi. Temuantemuan tersebut menunjukkan bahwa pemberian lidokain intravena memberikan pengurangan yang bermakna terhadap nyeri yang diderita subjek.

Nilai SAV dan parameter hemodinamik yang diamati pada 6 jam pasca operatif, tidak berbeda bermakna pada kedua kelompok. Penelitian ini menggunakan pethidin intravena sebagai analgetik intraoperatif dan ketorolac sebagai analgetik post-operatif . Durasi kerja dari pethidin dapat mencapai 12 jam pasca pemberian, ${ }^{7}$ sehingga dimungkinkan perbedaan yang tidak bermakna tersebut karena obat analgetik intraoperatif yang digunakan masih bekerja, bukan karena efek dari ketorolak .Dugaan tersebutdidukung pengamatan bahwa pada kelompok placebo, terjadi peningkatan dalam rerata SAV setelah 12 jam pasca operatif, dimana analgetik post-operatif ketorolac masih tetap diberikan.

Hasil penelitian ini juga menunjukkan bahwa terdapat perbedaan waktu yang bermakna pada dimulainya rescue analgetik pada kedua kelompok. Hal tersebut menunjukkan bahwa pada pemberian lidokain intravena terjadi pengurangan kebutuhan terhadap opioid. Hal ini sesuai dengan hasil penelitian Cui et al yang menujukkan bahwa penggunaan lidokain dapat menurunkan kebutuhan terhadap morfin pasca operatif. $^{4}$

Kekhawatiran penggunaan lidokain intravena adalah ketidakstabilan hemodinamik karena blockade pada kanal natrium sistem kardioSAVkuler, sehingga menyebabkan bradiaritmia. ${ }^{2}$ Pada salah satu subjek terjadi bradikardia pasca intubasi, sebelum analgetik lidokain mulai diberikan, sehingga subjek tersebut dieksklusikan. Namun demikian, pada keseluruhan subjek yang lain, tidak ditemukan adanya bradiaritmia durante operatif. Banyak faktor yang dapat mempengaruhi terjadinya bradikardia pasca intubasi, antara lain reflex vagal, adanya penyakit jantung preoperative yang tidak terdeteksi, riwayat pengobatan dengan penyekat beta, dan sebagainya. Pada subjek tereksklusi lainnya terjadi perdarahan massif, sehingga dikhawatirkan akan mempengaruhi hasil pengamatan hemodinamik pasca operatif, maka pada subjek tersebut pemberian lidokain intravena dihentikan. 


\section{SIMPULAN}

Pemberian lidokain 1,5 mg/kg intravena memberikan SAV nyeri $<5$ pada $83 \%$ pasien pasca laparotomi dan dapat menurunkan kebutuhan penggunaan analgetik opioid dalam pengelolaan nyeri pasca laparotomi. Diperlukan penelitian lebih lanjut mengenai dosis minimal lidokain intravena yang efektif dalam pengelolaan nyeri pasca operasi, dan aplikasinya dalam pasien pasca operasi lainnya.

\section{DAFTAR PUSTAKA}

1. Caio Marcio Barros de Oliveira, TSA, et al. Intraoperative intravenous lidocaine.Revista Brasileira de Anestesiologia, 2010;60(3): 325-333.

2. Louise Vigneault, MD, et al. Perioperative intravenous lidocaine infusion for postoperative pain control : a meta-analysis of randomized controlled trials. Canadian J.Anesthesiologists Society, 2011;58:22-37.
3. BK Baral, et al. Perioperative intravenous lidocaine infusion on postoperative pain relief in patients undergoing upper abdominal surgery.Nepal Med Coll J, 2010; 12(4): 215-220.

4. Weihua Cui, et al. Systemic administration of lidocain reduces morphine requirements and postoperative pain of patients undergoing thoracic surgery after propofol-remifentanil-based anaesthesia. European Journal of Anesthesiology, 2010;27:41- 6 .

5. Abdourahamane Kaba, MD, et al. Intravenous lidocaine infusion facilitates acute rehabilitation after laparoscopic colectomy. American Society of Anesthesiologists, 2007; 106:11-8.

6. Kaba.A, et al. Acute rehabilitation program after laparascopic colectomy using intrvenous lidocain. Annual Meeting of the European Society of Anesthesiologists, 2005;105:53-8.

7. Marsaban A, Maas EM, Bagianto H. Ilmu Pengetahuan dasar, mekanisme fisologi nyeri. In: Chandra S. Panduan Tatalaksana Nyeri Perioperatif. Jakarta:Perhimpunan Dokter Spesialis Anestesiologi Dan Reanimasi Indonesia. 2009 .p. 1-25 